\title{
EXPERIMENTAL MODAL ANALYSIS OF PASSENGER CAR ENGINE OIL PAN USING FEM AND FFT ANALYZER
}

\author{
Ramesh S ${ }^{1}$, Maruthi Prashanth B $\mathbf{H}^{2}$ \\ ${ }^{1}$ Assistant Professor, Department of Mechanical Engineering, Beary's Institute of Technology, Manglore-574153, \\ India \\ ramaghalli@gmail.com \\ ${ }^{2}$ Assistant Professor, Departmenbt of Mechanical Engineering, Beary's Institute of Technology, Manglore-574153, \\ India \\ bhmprashanth@gmail.com
}

\begin{abstract}
Generally a lubricating oil sump is used to lubricate all the moving components in any IC engine. A wet sump design for engines uses the crankcase as a built-in reservoir for oil. In general, oil sump is subjected to engine excitation frequencies which may cause resonance if it coincides with natural frequencies of the oil sump. This resonance may result into severe damage. This paper deals with the study of existing oil sump of a sedan class car. Mainly this paper will focus on the modal analysis of the oil sump by Experimental analysis and its comparison with FEA results. Oil sump also affects NVH characteristics of engine. Modal analysis of oil sump is done using MSC Nastran to determine the vibration characteristics of sump. The results show that the range of natural frequency is avoided marginally and the total deformation is within the range.
\end{abstract}

Keywords: Oilpan,FEM , Mode shapes, FFT,Frequency Response Function

\section{INTRODUCTION}

As human heart supplies blood to various parts of body, with same analogy an oil pump is a heart of lubricating oil system which supplies lubricating oil to all the moving parts of the engine. In most engines, which use a wet sump system, the oil is collected in a oil pan with adequate capacity at the base of the engine. Such oil pan is also known as the 'oil sump' where oil is pumped to the bearings and other interfaces by the oil pump, internal to the engine. An internal oil pump is generally more difficult to replace, but that is dependent on the engine design. In the automotive industry, for instance, the passenger's acoustic comfort has become an important commercial asset. This affects the efforts in reducing the weight of vehicles, which are mainly motivated by potential fuel savings but quite often induce substantial noise and vibration levels. In order to incorporate these acoustic criteria in the design process, there is a strong need for numerical prediction tools that provide the necessary insight in the physical phenomena which govern the acoustic behaviour of complex real-life systems and that allow a reliable evaluation of different design alternative.

This paper is emphasis on the systematic approach for modal analysis using Finite element technique.

A Sedan class engine oil pan has been modeled in CAD Software CATIA V5 R17 and the finite element modeling of an engine oil pan has been carried out using CAE Software ALTAIR HYPERWORKS V12. Normal mode analysis and
Frequency response analysis has been carried out in MSC.NASTRAN and velocity results will be input to the acoustic analysis and an experimental modal test has been carried out to check the model integrity. Experimental vibration test has been carried out to obtain the accelerations coming on to the engine oil pan structure by the ME 'Scope Test Lab IMPACT TESTING system. The experimental stamped steel oil pan as shown in fig 1

The literature related to the analysis of oil pan reveal the following facts. Brian J. Schwarz et al.[1]. This paper, gives all of the main topics associated with experimental modal analysis (or modal testing), including making FRF measurements with a FFT analyzer, modal excitation techniques, and modal parameter estimation from a set of FRFs (curve fitting). [2] Discusses the use of Operational Modal Analysis for experimentally determining the Eigen frequencies, damping ratios and mode shapes of a vibrating structure. That gives knowledge of both the theory and practical aspects of applying Operational Modal Analysis to engine run-up data. Naveen Kumar [4] carried out work on the 1.8 liter diesel engine oil pan. In this paper modal analysis (free-free) of engine oil pan was carried out using finite element analysis and experimental modal analysis software tools. Frequency response analysis was carried out to extract the velocity from the side face of the oil pan. The output of the frequency response analysis was an input for the noise analysis. The FEA modal analysis and experimental analysis correlated within a considerable limit. [3]In this paper the experiment is carried out on the 
identifications noise resources of a truck engine oil pan. The research results show that the fan, fuel pump, oil pan, and turbocharger noises are the main factors of external accelerating noise. In this paper main noise source of vehicle was determined by combining the sound intensity test and the frequency spectrum analysis. The percentage contributions of noise to the engine from its different parts are as follows: Engine body-33.33\%, Oilpan-32.65\%, Injector-9.23\%, Turbochager-8.13\%, Air compressor$4.13 \%$.

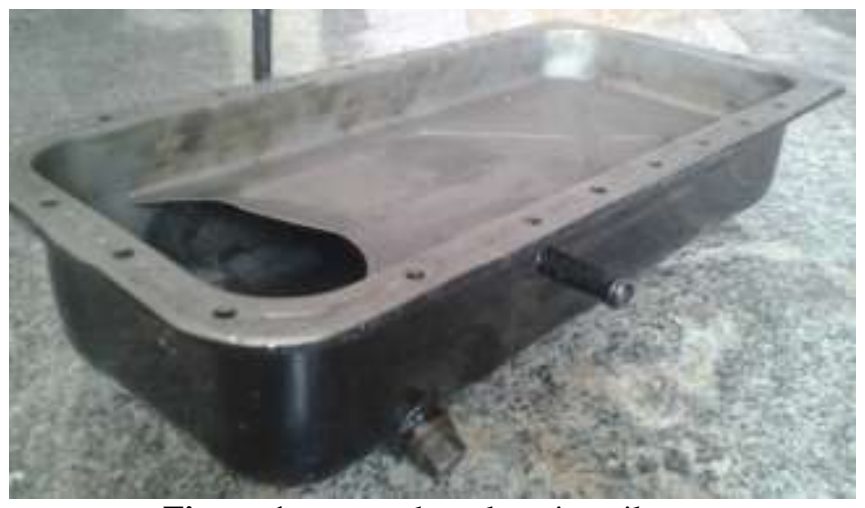

Figure 1: stamped steel engine oil pan

\section{MODLELING AND FEM ANALYSIS OF OIL}

\section{PAN}

MODELING; The modeling of oil pan was done using CATIA V5 R17 as shown in figure 2.

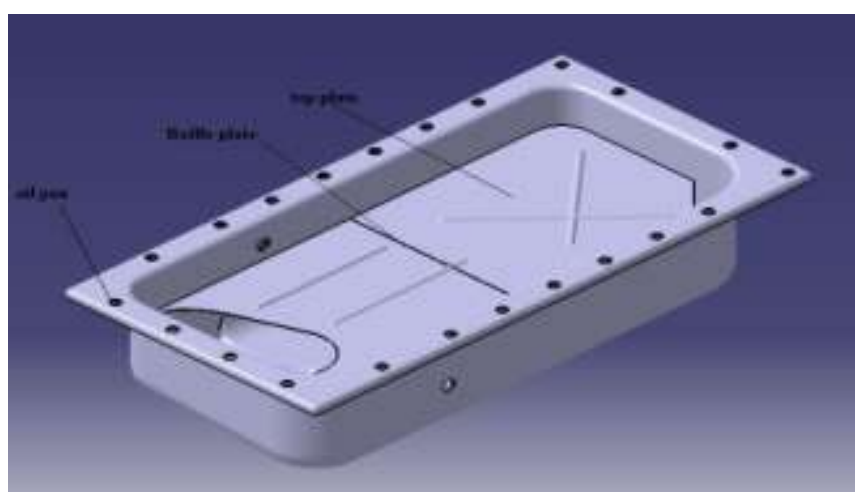

Fig 2. CATIA model of oil pan

FINITE ELEMENT METHOD: The finite element Method is a powerful tool for the numerical solution of a Wide range of engineering problems. With the advances in Computer Technology and CAD systems, complex problems can be modeled with relative ease.Several alternatives Configurations can be tested on a computer before the first Prototype is built.

Here shell meshing is made at oil pan. In shell meshing triangular and quadrilateral elements are used. At holes RB2 elements are used. While meshing 16500 quad elements and 122 triangular elements are used in shell meshing. Twenty four RB2 elements are used at the top face of oil pan. The meshed model of oil pan as shown in fig 3. TABLE I shows material properties of an oil pan.

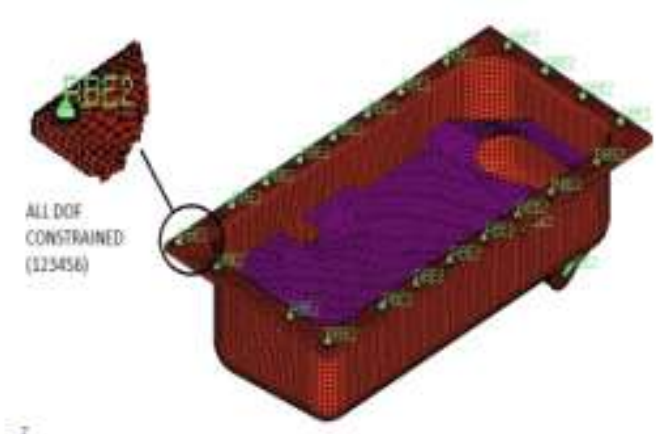

Gnbrithiser

Fig3. Oil pan Meshed Model

Analysis of oil pan is done by using MSC NASTRAN.The starting six natural frequency mode shapes are as shown in fig4. The starting six natural frequency is tabulated in table II

Table1. Material Properties of an oil pan

\begin{tabular}{|l|l|l|}
\hline PROPERTIES & VALUE & UNIT \\
\hline Young's Modulus & $2.1 \mathrm{e} 5$ & $\mathrm{~N} / \mathrm{mm} 2$ \\
\hline Poisson 'ratio & .3 & \\
\hline Density & $7.9 \mathrm{e}-09$ & TONNE $/ \mathrm{mm}^{3}$ \\
\hline Mass & $1.721 \mathrm{e}-3$ & TONNE \\
\hline
\end{tabular}

Table II. First six natural frequencies

\begin{tabular}{|c|c|c|c|c|c|c|}
\hline Modes & 1 & 2 & 3 & 4 & 5 & 6 \\
\hline Frequency(Hz) & 141 & 194 & 258 & 314 & 355 & 440 \\
\hline
\end{tabular}
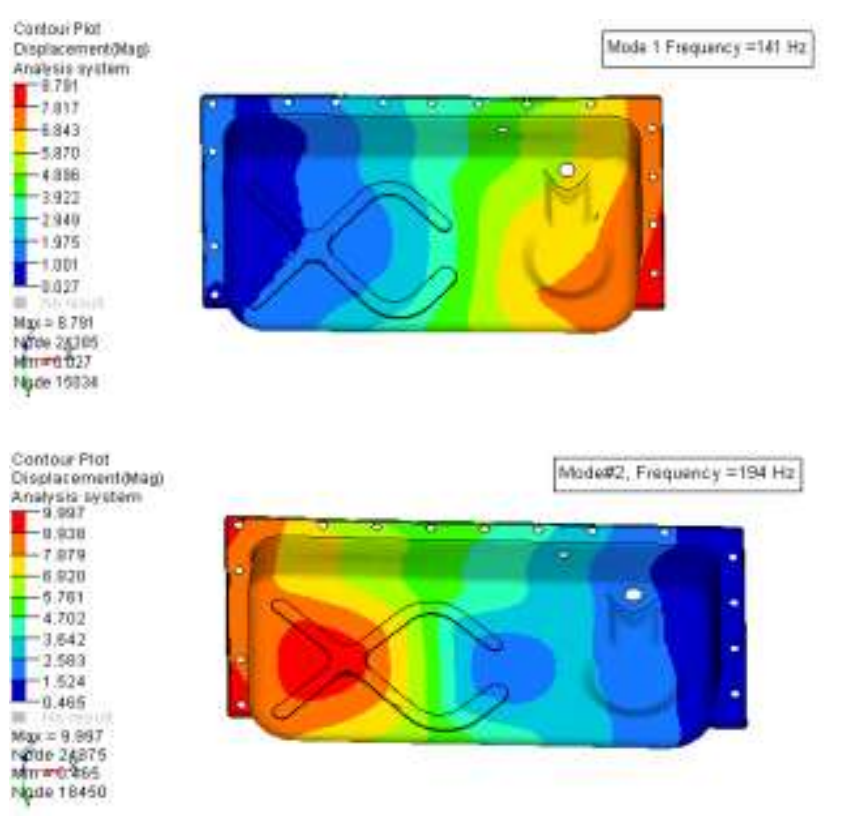

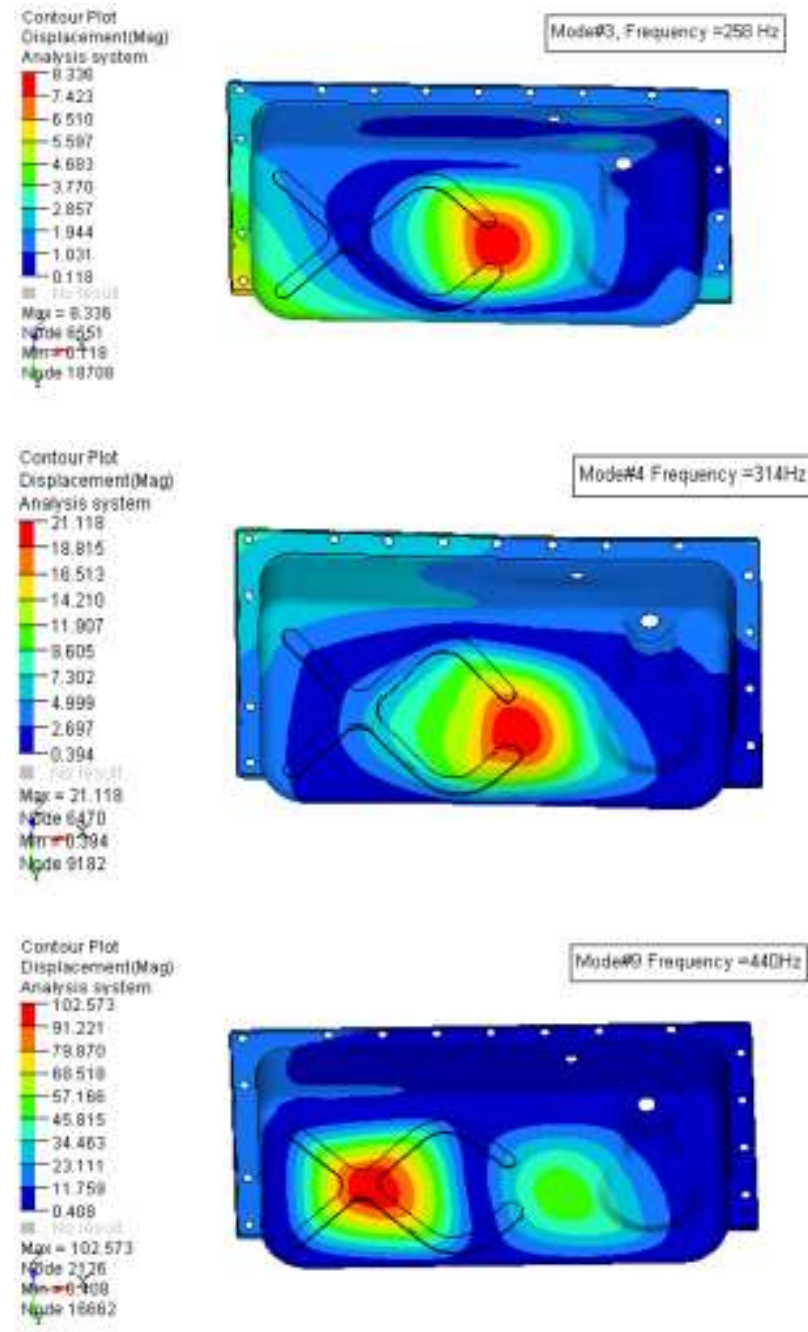

Fig 4; Mode shapes

\section{EXPERIMENTAL NORMAL MODAL} ANALYSIS

Experimental analysis was conducted on sedan class engine oil pan to validate the natural frequencies obtained from finite element analysis. The task included preparing the experimental setup for modal analysis, hanging the engine oil pan, mounting the accelerometer with the adhesive, making FRF measurement and then post processing to get the natural frequencies and mode shapes. The experimental modal analysis of an engine oil pan was carried out using ME'SCOPE impact testing system.

A typical measurement set-up in a laboratory environment should have three constituent parts. The first part is responsible for generating the excitation force and applying it to the test structure, the second part is to measure and acquire the response data; and the third part provides signal processing capacity to derive FRF data from the measured force and response data as shown in fig5

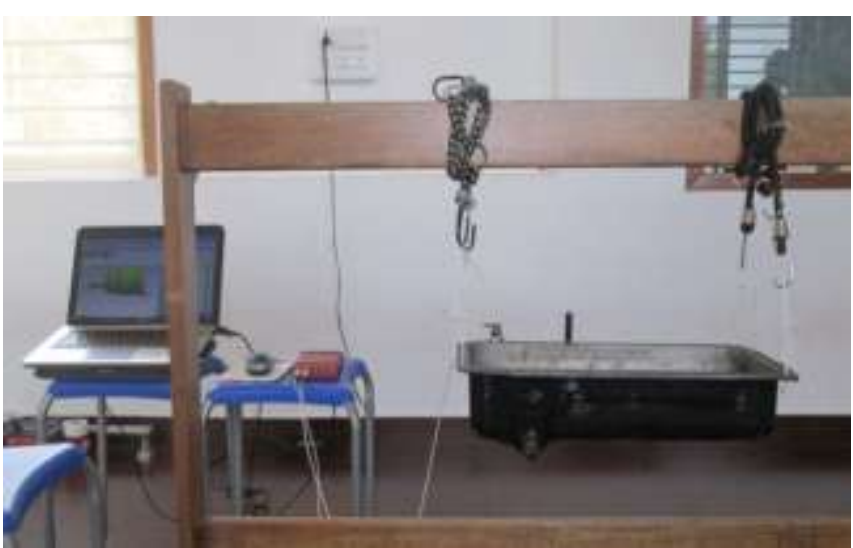

Figure 5: Experimental set up for Modal Analysis

Excitation points were marked on the engine oil pan as shown in fig 6 , such that the required global modes of the engine oil pan can be captured accurately. Total fifty eight points were marked on the engine oil pan these points are shown in fig 6

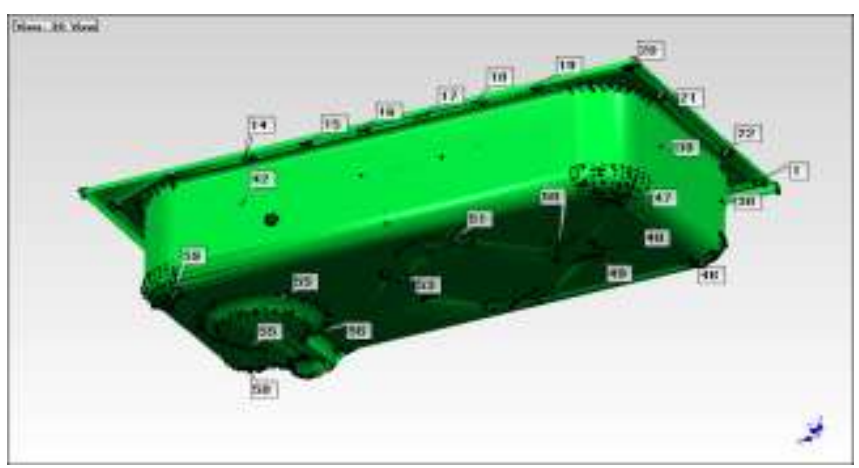

Figure 6: Excitation points marked on oil pan

The engine oil pan is hanged to the vertical support with the help of elastic chords to simulate free-free boundary condition. A Uni-axial accelerometer was mounted at point 1 on oil pan using bee-wax. The impact hammer output is connected to channel port 1 of the analyzer and the outputs of the UNI-axial accelerometer were connected to the channel ports 2 . The sensitivity of the accelerometer and the impact hammer were set in the measure panel of the FRF analyzing software in ME'SCOPE TEST LAB, Triggering settings, bandwidth setting, and windowing options is then made with few drive point measurements. The input hammer signal, output accelerometer signal and final FRF graph as shown in fig 7. Frequency Response Function plots is obtained by exciting each of the point on the engine oil pan. Totally obtain 59 FRF graphs. The FRF graphs of few points as shown in figure6. 


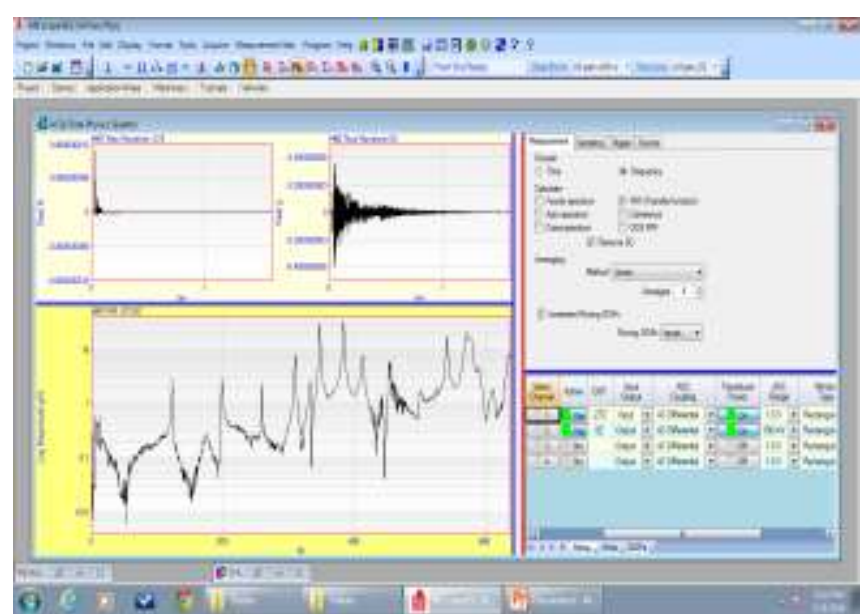

Figure 7: Experimental FRF graph.
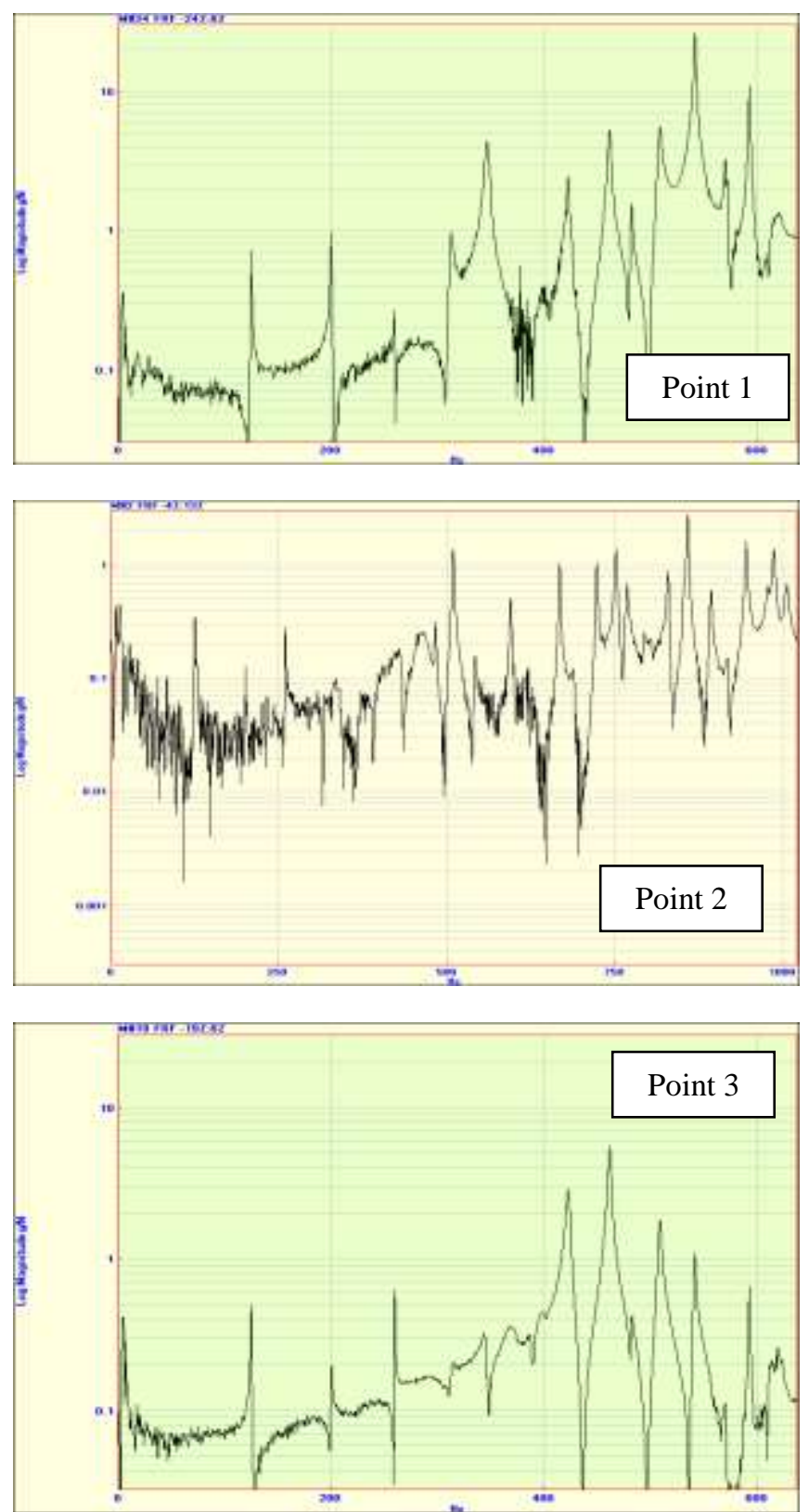
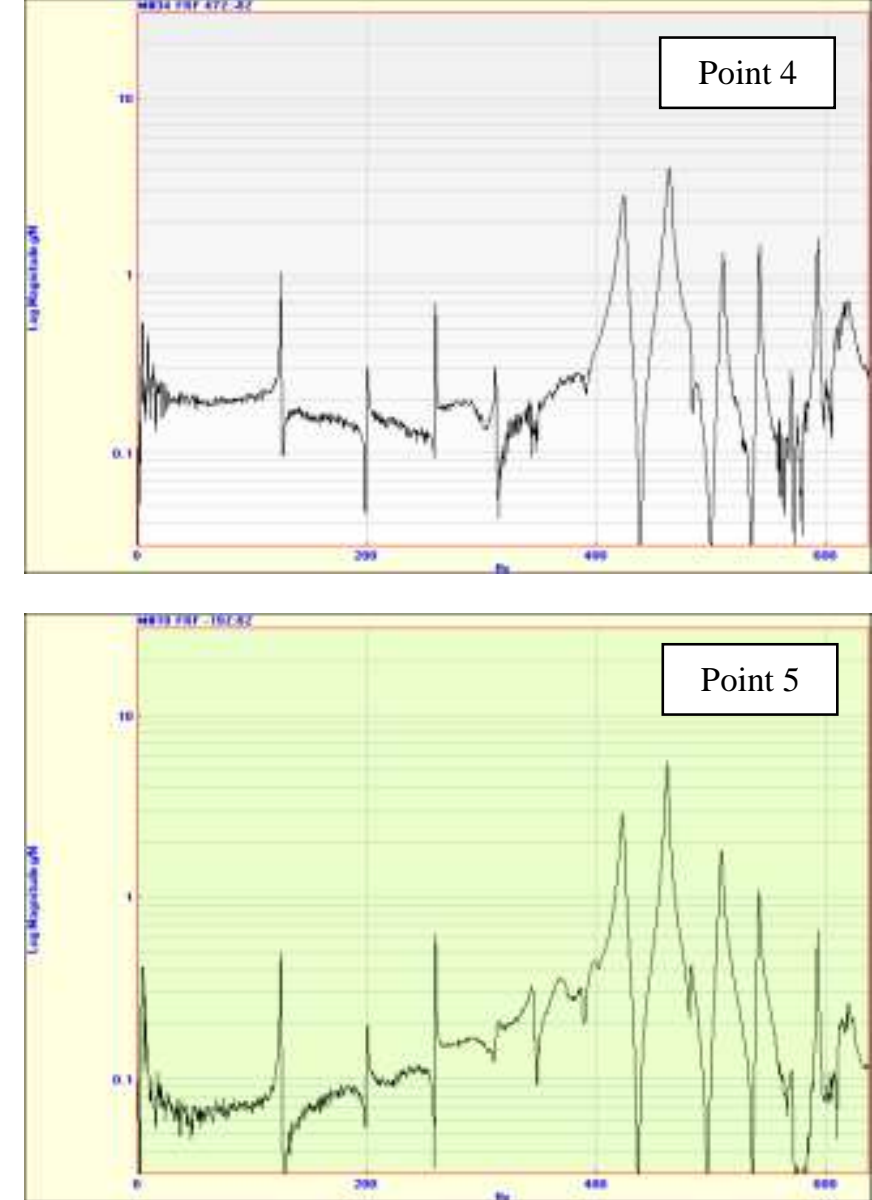

Fig.6.Frequency Response Function of different points on oil pan

Selecting the different bandwidth at peak points gives us the natural frequencies of the engine oil pan, as shown in fig 7 The first seven natural frequency obtained is tabulated in Table III

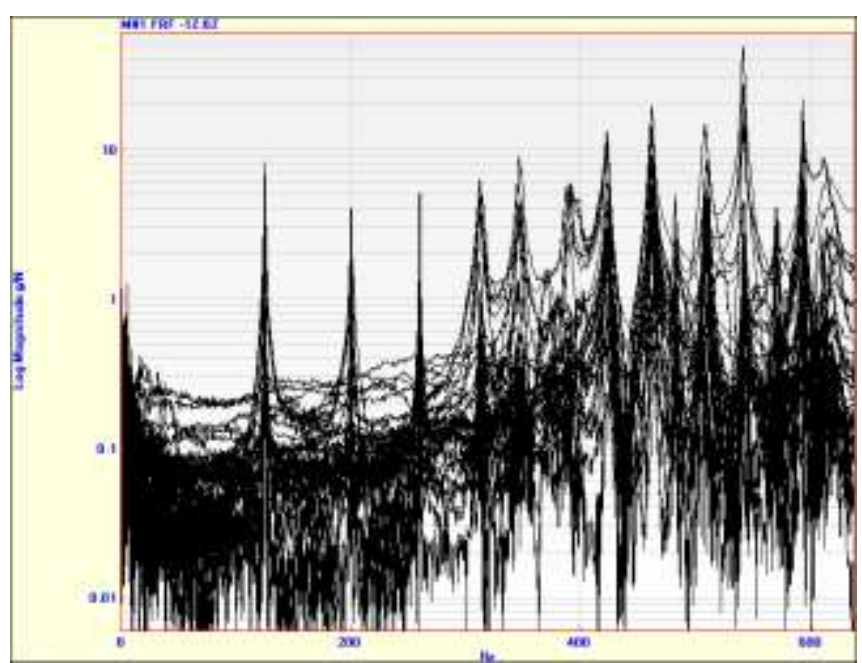

Figure7: Combing all 59 FRF Graphs 
Table III: First seven natural Frequency and damping values by FFT analyzer

\begin{tabular}{|c|c|c|c|c|}
\hline $\begin{array}{l}\text { Seloct } \\
\text { Shape }\end{array}$ & $\begin{array}{l}\text { Frecinency } \\
\text { (1) Tre) }\end{array}$ & Defing & Unt & (x) \\
\hline 1 & 125.404755 & 0.252530336 & Hz & 0.201371759 \\
\hline 2 & 200.633438 & $0.3134167 / 7$ & Hz & 0.156213447 \\
\hline 3 & 200.50943 & $0.15907 / 197$ & $\mathbf{H z}$ & 0.061053882 \\
\hline 4 & 313.174683 & 1.10044968 & Hz & 0.35138309 \\
\hline 5 & 347.043671 & 1.04602981 & Hz & 0.301410198 \\
\hline 6 & 424.13858 & 1.80261993 & ltz & 0.425003469 \\
\hline 7 & 462637512 & 1.4910531 & He & 0.3222292358 \\
\hline
\end{tabular}

\section{IV.RESULTS AND DISCUSSION}

The comparison first six natural frequencies of vibration of oil pan by FEM package and FFT analyzer tabulated in the below TABLE IV. This table clearly shows that the natural frequency obtained by both methods agree with each other.

Table IV; Comparison of FEA and FFT Results

\begin{tabular}{|c|c|c|}
\hline Mode no & $\begin{array}{l}\text { Experimental } \\
\text { Results in Hz }\end{array}$ & $\begin{array}{l}\text { FEA Results in } \\
\text { Hz }\end{array}$ \\
\hline 1 & 125 & 141 \\
\hline 2 & 200 & 194 \\
\hline 3 & 260 & 258 \\
\hline 4 & 313 & 314 \\
\hline 5 & 347 & 355 \\
\hline 6 & 424 & 440 \\
\hline
\end{tabular}

The frequency values obtained experimentally, matches closely with that of the FEA frequency values. The percentage of error obtain is below $15 \%$.

\section{V.CONCLUSION}

A successful effort has been made to predict the Eigen values and Eigen vectors of engine oil pan by numerical simulation as well as experimental analysis under free-free (normal modal) condition. The finite element model shows an acceptable correlation with the experimental results for measuring the natural frequencies and mode shapes. So the FE model can be used for modal frequency response analysis, however, in order to rely more on the results of finite element analysis, it is better to make necessary updates to FE model using the experimental results.

\section{REFERENCES}

[1] Brian J. Schwarz \& Mark H. Richardson "EXPERIMENTAL MODAL ANALYSIS" Vibrant Technology, Inc. Jamestown, California 95327, October, 1999.

[2] S. Ringwelski, T. Luft and U. Gabbert, "Design of active noise and vibration control for car oil pans using numerical simulations", Montreal, Quebec, Canada, October 2009.

[3] Bart Peeters, Jean-Sébastien Servaye and Joon De Cock, "Truck applications of Operational Modal
Analysis", LMS International, Interleuvenlaan 68, B3001 Leuven, Belgium.

[4] L. Naveen Kumar-"Reduction of Noise from 1.8 Liter Diesel Engine Oil Pan.

[5] Huibin Li, Jichun Liu -"Study on Identificfation of Noise Resources and Truck's Noise Reduction". Beijing, 100081.

[6] ME'scope VES 5.0, Tutorial Manual, Volume IABasic Operations.

[7] Thirupathi R. Chandrupatla \& Ashok D.Belegundu "Introduction to Finite elements in engineering" $3^{\text {rd }}$ edition,2001. 